\title{
Writing an Abstract for a Scientific Conference
}

\author{
Simkhada $\mathrm{P}^{1-3}$ van Teijlingen $\mathrm{E}^{2-4}$ Hundley $\mathrm{V},{ }^{4}$ Simkhada $\mathrm{BD}^{5}$
}

\begin{abstract}
${ }^{1}$ School of Health and Related Research (ScHARR)
University of Sheffield, Sheffield, England, UK

${ }^{2}$ Manmohan Memorial Institute of Health Sciences

Tribhuvan University, Kathmandu, Nepal

${ }^{3}$ Nobel College, Pokhara University Nepal

${ }^{4}$ School of Health and Social Care

Bournemouth University, England, UK

${ }^{5}$ Inter

ABSTRACT

For most students and junior researchers, writing an abstract for a poster or oral presentation at a conference is the first piece they may write for an audience other than their university tutors or examiners. Since some researchers struggle with this process we have put together some advice on issues to consider when writing a conference abstract. We highlight a number of issues to bear in mind when constructing one's abstract.
\end{abstract}

Corresponding Author

Padam Simkhada

School of Health and Related Research (ScHARR)

University of Sheffield, Sheffield, England, UK

\section{KEYWORDS}

Abstract writing, conference, oral presentation, poster, scientific writing

E-mail: p.simkhada@sheffield.ac.uk

\section{Citation}

Simkhada P, van Teijlingen E, Hundley V, Simkhada BD. Writing an Abstract for a Scientific Conference. Kathmandu Univ Med J 2013;43(3):262-265.

\section{INTRODUCTION}

It is recognised that disseminating scientific information to a wide-range of audiences is of enormous importance. Such dissemination helps to ensure that vital scientific information, such as research findings reaches other researchers, policy-makers and the wider general public. One way of communicating with academic colleagues is through scientific conferences, which are often venues where new ideas are tested with a critical audience, (preliminary) findings are presented and/or methodological issues discussed. Regardless as to whether academics present an oral paper or a poster they usually are expected to submit a short abstract first to the organisers of the conference.

An abstract is a succinct summary of a longer piece of work, which is published in isolation from the main text and should therefore stand on its own and be understandable without reference to the longer piece. ${ }^{1}$ A conference abstract is a short piece of written work, often not more than 200 or 300 words, which serves at least three separate functions. Each conference will have its own guidelines as to how an abstract should be prepared. If authors do not follow these guidelines their abstract is more likely to be rejected. The first function of an abstract is to convince the conference organisers that your paper is worth accepting. Hence, it tells the organisers what message you want to convey and how this fits into the general theme of the conference. Secondly, after you have been accepted to present a paper or a poster at the conference your abstract will end up in the conference programme or abstract book and act as an advert for your talk or poster. Capturing the attention of the conference goer is the other key role of your abstract. Conference goers will base their decision to attend your paper, or any of the other ones on-going in the parallel session: on the contents of your short abstract. In theory, if you write an interesting abstract that is aimed at the target audience then you will also accomplish function 1 (that of convincing the conference organisers). Finally, after the conference has long finished, your abstract will act as a permanent record, especially if the conference programme or abstract book is published (either in hard copy or on the web).

The authors between them have submitted many conference abstracts to scientific conferences across the globe. Moreover, they will also have been on the 
receiving end of conference abstracts, as all authors have reviewed, accepted and rejected abstracts for international conferences.(Box 1)

Conference presentations of posters are often a first step in exploring your research ideas or findings with the wider academic community; with people who have similar interests. It is often a good opportunity to get feedback from out with your own circle of colleagues and fellow postgraduate students. As with all academic writing, read the instructions first. Establish what the closing date is for submitting an abstract, and find out whether or not there are themes or streams in to which your abstract needs to fit. But before starting your first draft of the abstract pause a few minutes and ask yourself the question: "What exactly is my idea or message, and how does it fit into the advertised conference?" More generally, think about some conferences you have attended in your own university or institution and ask yourself: "Which conference did I learn most from?" or "Which paper or poster did I wish had been mine?" The final preparation prior to drafting the abstract is finding out the required format and word limit. Many health and clinical conferences require abstracts in a formal structure, usually something like Background, Methods, Results, and Conclusions, but social science conferences, like social science journals, can be less prescriptive in their format for the abstract.

\section{Selecting a conference}

In the same way that not all journals are an appropriate place in which to publish your paper, not all conferences will have an appropriate audience for your paper. ${ }^{2}$ Within the health field, there are disease focused conferences, health systems conferences, health psychology conferences, medical sociology conferences, health promotion conferences, and others. Choosing the right conference involves careful consideration of the aims of the conference and the target audience. There are international conferences with thousands of delegates and there are local departmental conferences with 25 or 30 participants. Bigger is not always better, and you need to identify the best way of disseminating your work. It is worth finding out who is on the conference committee and what their background is.

\section{Box 1. Six steps to writing an abstract.}

Having identified an appropriate conference at which to present your work or ideas, you should then follow these steps:

1. Find the stream where your topic best fits;

2. Decide if your topic is an empirical study or programme / policydriven;

3. List the main points in bullet form;

4. Convert the bullet points into linking sentences;

5. Provide descriptive and interesting title; and

6. Re-check your abstract using the checklist and submit.

\section{Find the stream where your topic best fits}

Most conference organising committees divide the field into streams. If this is the case in your conference then:

- Look at all the possible streams;

- Select the stream that your topic best fits in to;

- Discuss with your peers or other professional people (if you are not sure).

\section{Decide if your topic is an empirical study or programme/ policy-driven}

There are essentially three kinds of abstracts:

i) Research-based

- Background

- Methods

- Results

- Conclusions and recommendations

ii) Issue / programme-based

- Issues

- Descriptions

- Lessons learnt

- Recommendations

iii) Symposia or round table discussions which are less structured and more discursive.

\section{List the main points in bullet form}

Writing your main points in bullet form will help you to limit what you are saying. ${ }^{3}$

- How can I describe my research? How can I clearly state the objectives of my presentation?

- Think about your target audience: who are they?

- Tell them what you are going to say - this is the "who, what, when, where and how" of your presentation.

\section{Convert the bullet points into linking sentences}

- Make sure your abstract reads easily with each sentence following into the next;

- In the final draft, bullets or numbers should only be used for lists;

- Remember that this is only an abstract; use a clear, direct writing style. Your abstract should be accessible to both specialists and non-specialists, so make sure that it is jargon free.

\section{Provide a descriptive and interesting title}

- In thinking of your title, be descriptive and simple (but not too brief).

- "Children, challenges and changes"- looks cute but doesn't tell us which children, which challenges, or which 
changes.

- "Youth recreation centre"- too general.

- "HIV/AIDS in Nepal"- too brief.

- "HIV/AIDS knowledge among female sex workers in Nepal"- more descriptive and clearer,

- Your title needs to help the reviewers categorize your presentation and may eventually help conference delegates find your session;

- Don't try to be too smart in developing your title. Although you want to make it interesting, the title needs to describe the topic.

\section{Re-check your abstract using the checklist andsubmit}

- Could people from other fields of study understand it?

- Does it give a sense that someone will get more from the presentation than from just reading the research paper?

- Is it clear and concise?

- Have acronyms been explained?

- Is there too much introductory material/material that sets the context?

- Has someone checked it over to ensure it is free of grammatical errors, spelling errors and awkward sentence structure, and that it is factually correct?

\section{Box 2. Example of good abstract( Citation award abstract).}

Simkhada P, Bhatta P, Regmi P \& van Teijlingen E (2006). Risky sexual behaviour among trekkers guides in Nepal, paper presented 9th International Congress of Behavioural Medicine, November 29- December 2, 2006, Bangkok Thailand

There is evidence that significant sexual interaction between travellers and tourist guides takes place in Nepal, but little is known about the sexual activity of trekkers' guides. The main aim of this study was to identify the (risky) sexual behaviours among male trekking guides in Nepal.

A self-administered questionnaire survey (total 324) and in-depth interview (total 21) were conducted using snowball sampling. Majority of respondents (95.4\%) were literate and more than twothird was fairly young and $61 \%$ married. About $28 \%$ had both Nepali and foreign girl friends and about $85 \%$ drank some kind of alcohol. Knowledge about HIV/AIDS was high (97\%) comparing to other STIs and significant association was found between ethnic background, education and the knowledge. Most of the respondents (95.4\%) were sexually active and $58.1 \%$ had sexual practice before age 18 . Nearly two-third had sexual relationship with foreign women. The duration of working as a guide and sexual intercourse was found significantly associated $(p<0.05)$. Nearly all $(95 \%)$ believed that condoms are an effective method of contraception and $60 \%$ respondents believed that condom could reduce sexual pleasure. Nearly two-third (65\%) used condoms during the sex with foreign women and only $8 \%$ of the respondents believed that they would get HIV from their existing sexual practice.

Most of the trekker guides have sexual relation with foreign women and irregular use of condoms was common among them. Although knowledge about sexual health issues among trekker guides is high, some misconception and myths still encourage them to perform unsafe sexual practices. These findings suggest that there is an urgent need to revise the existing training curriculum and training package for trekking guides and implement appropriate health promotion interventions.
- Does the abstract meet the technical requirements? Are the conference's word limits and other guidelines (such as font size, spacing and margins) absolutely respected?

Common mistakes

Using more words than allowed. One of us (EvT) has reviewed abstracts submitted to a conference where the word limit was strictly adhered to and all abstracts where automatically cut at 250 words and the last few words/ sentences were simply removed. Some abstracts were rejected because without that final sentence they simply did not make sense.

Offering to present findings you don't have yet. It is not uncommon for international conferences to have an abstract deadline of six to eight months prior to the actual event. People with work in progress are often tempted to put in an abstract 'findings will be available at the time of the conference'. Most conference organizers are reluctant to include papers based on such promises. Conference organizers are often experienced academics and they know that there might be all sorts of delays in the research process; such delays can easily result in expected data simply not being available at the time of the conference.

Submitting the same abstract to present at consecutive conferences. Conference organizers sometimes insist that only new material is submitted for presentation. Although organizers rarely worry about in-house presentations, they may say that papers should not previously have been presented at a national or international arena. This may extend to manuscripts published in journals as well.

\section{References in Abstracts}

It is unusual to see references in research-based abstracts; however it may be appropriate for other types of abstract. The question of whether to include references depends on the required format, so it is important to read the guidelines carefully.

\section{What happens after submitting your abstract?}

The process by which abstracts are reviewed may vary from conference to conference. In some cases review may be made by a conference scientific committee, however larger conferences frequently use blind reviewing done by external reviewers (in the same way that manuscripts are reviewed for journals). External reviewers allocate scores based on set criteria, and these scores guide the scientific committee in short-listing the abstracts for presentation. ${ }^{4}$ Some things to consider are:

- Timing between submission, decision, and registration

Conferences usually have a fairly strict timeline. The guidelines usually state a date by which you will be notified as to whether your abstract has been accepted. Once a decision has been made regarding the abstract you will need to register to attend the conference. If you fail to register by the deadline, is likely that your paper will be removed from the conference schedule. 
- If accepted - deadline for full papers

You may also be required to submit a full paper by a specified date. In such cases these papers are included in a conference book of papers.

- Posters instead of papers

Some conferences may offer the option of poster

\section{REFERENCES}

1. Emerald Group Publishing Limited. How to Write an Abstract [internet] 2012 [accessed on 06.09.2012]. Available from: http://www. emeraldinsight.com/authors/guides/write/abstracts.htm?part=1\#2.

2. van Teijlingen $E$, Simkhada $P$ and Rizyal $A$. Submitting a paper to an academic peer-reviewed journal, where to start? Health Renaissance. 2012; 10 (1): 1-4. presentation if the organisers are unable to fit all the suitable papers within a programme. There has been a tendency to view posters as inferior of paper presentation, because they were displayed in out of way places or during lunch breaks. However, many conferences now have a specific session for poster viewing.

3. Happell B. Conference presentations: a guide to writing the abstract. Nurse Researcher. 2008; 15, 79-87.

4. Timmer A, Sutherland LR, Hilsden RJ. Development and evaluation of a quality score for abstracts. BMC Medical Research Methodology. 2003; 3: 2. 